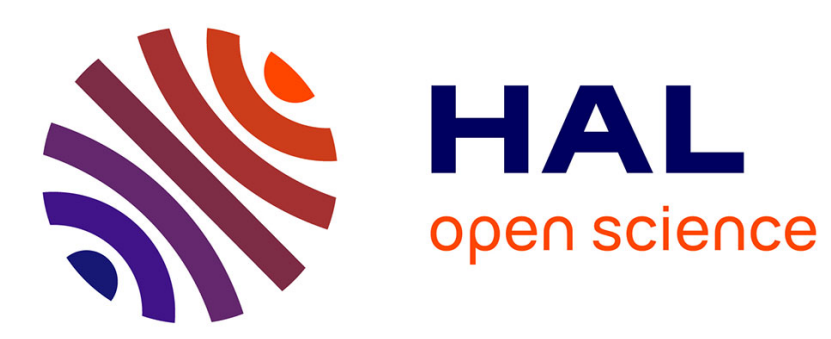

\title{
Rational land and housing bubbles in infinite-horizon economies
}

\author{
Stefano Bosi, Cuong Le Van, Ngoc-Sang Pham
}

\section{To cite this version:}

Stefano Bosi, Cuong Le Van, Ngoc-Sang Pham. Rational land and housing bubbles in infinite-horizon economies. 2016. halshs-01314609

\section{HAL Id: halshs-01314609 \\ https://shs.hal.science/halshs-01314609}

Submitted on 11 May 2016

HAL is a multi-disciplinary open access archive for the deposit and dissemination of scientific research documents, whether they are published or not. The documents may come from teaching and research institutions in France or abroad, or from public or private research centers.
L'archive ouverte pluridisciplinaire HAL, est destinée au dépôt et à la diffusion de documents scientifiques de niveau recherche, publiés ou non, émanant des établissements d'enseignement et de recherche français ou étrangers, des laboratoires publics ou privés. 


\section{Documents de Travail du

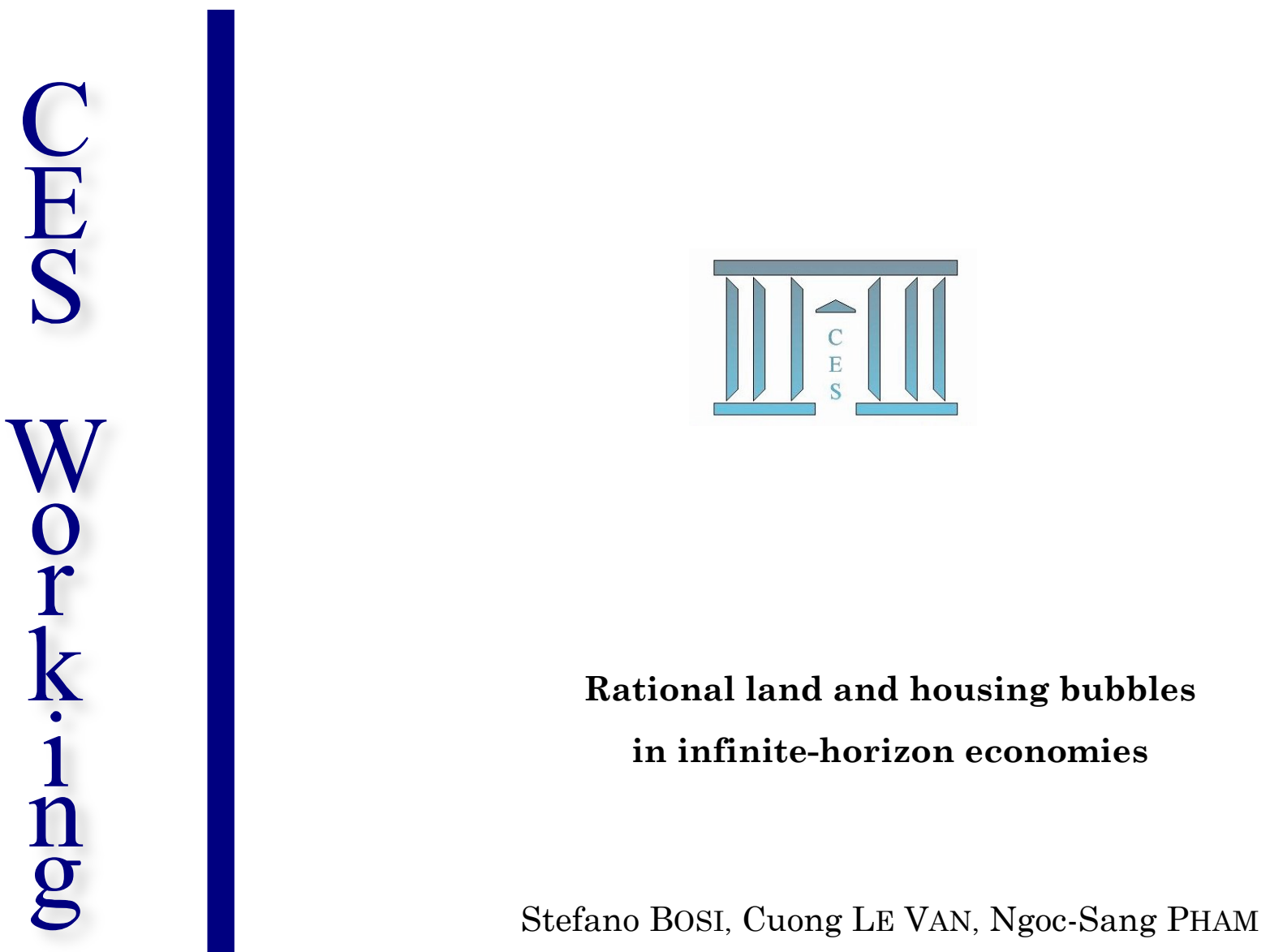

2016.27

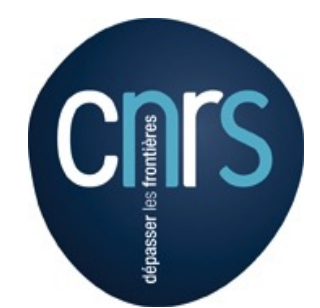




\title{
Rational land and housing bubbles in infinite-horizon economies*
}

\author{
Stefano BOSI ${ }^{\dagger} \quad$ Cuong LE VAN ${ }^{\ddagger} \quad$ Ngoc-Sang PHAM ${ }^{\S}$
}

February 13, 2016

\begin{abstract}
This paper considers rational land and housing bubbles in an infinite-horizon general equilibrium model. Their demands rest on two different grounds: the land is an input to produce while the house may be consumed.

Our work differs from the existing literature in two respects. First, dividends on both these long-lived assets are endogenous and their sequences are computed. Second, we introduce and study different concepts of bubbles, including individual and strong bubbles.
\end{abstract}

Keywords: infinite horizon, general equilibrium, land bubble, housing bubble. JEL classification: C62, D51, D9, G13.

\section{Introduction}

The existence of rational bubbles in general equilibrium model is a challenging issue since the early Eighties. Thinking bubbles in (dynamic) general equilibrium becomes indispensable to understand the real effects of financial crises. A general equilibrium approach captures the interplay between (financial and real) markets. If the issue of rational bubbles was initially raised in the OLG models, today it is mostly addressed in infinite-horizon intertemporal models.

Our paper is part of this recent literature and focuses on rational bubbles of specific long-lived assets, land and houses.

The conventional definition of asset bubble is the positive difference between equilibrium price and fundamental value. In general equilibrium models, price and fundamental value are endogenous, and the bubble as well. The equilibrium price is observed and determined by market clearing conditions, while the fundamental value depends on the definition of discounting and returns. Different definitions of fundamental value exist in literature.

The novelty of our paper is twofold.

(1) Land and houses are emblematic assets representing two alternative fundamental pricing mechanisms (land is used to produce good, and house is consumed and gives utility).

\footnotetext{
${ }^{*}$ The authors are very grateful to an anonymous referee useful remarks, comments, suggestions. They have helped us to substantially improve our previous version.

${ }^{\dagger}$ EPEE, University of Evry. Email: stefano.bosi@univ-evry.fr.

${ }^{\ddagger}$ IPAG, CNRS, and Paris School of Economics. Email: Cuong.Le-Van@univ-paris1.fr.

${ }^{\S}$ Corresponding author. EPEE (University of Evry) and LEM (University of Lille 3). Email: pns.pham@gmail.com. Ngoc-Sang Pham acknowledges the financial support of the LabEx MME-DII.
} 
The proofs of equilibrium existence are routine. Nevertheless, while most of the infinitehorizon models introduce exogenous sequence of dividends (for mathematical tractability), we compute instead endogenous dividends.

(2) We provide three different notions of bubble: the conventional one, of course, but also new definitions (individual and strong). We compare them to shed light on the financial underworld (assets) and its consequences on the real world (goods).

We focus first on a long-lived productive asset. Agents buy land today to produce a consumption good and resell it tomorrow. Any agent is consumer and producer at the same time and technology is supposed to be landowner-specific. One unit of land produces a no longer exogenous amount of consumption good. Our contribution rests on the concept of dividend of land denoted by $d_{t}$ and endogenously determined by the following asset-pricing equation:

$$
\frac{q_{t}}{p_{t}}=\gamma_{t+1}\left(\frac{q_{t+1}}{p_{t+1}}+d_{t+1}\right)
$$

where $p_{t}$ and $q_{t}$ are the prices of consumption good and land at date $t$ and $\gamma_{t+1}$ is the endogenous discount factor of the economy from date $t$ to date $t+1$.

We show that the land dividend lies between the lowest and the highest marginal productivities. The fundamental value of land at date 0 denoted by $F V_{0}$ is defined as a sum of discounted values of land dividends: $F V_{0}:=\sum_{t=1}^{\infty} Q_{t} d_{t}$ where $Q_{t}:=\gamma_{1} \cdots \gamma_{t}$ is the discount factor of the economy from the initial date to date $t$. We will show that the price of land consists of two parts. First, the reselling price of one unit of land. Second, the fundamental value, that is what one unit of land delivers in terms of dividend. A land bubble is said to exist when the equilibrium price of land (in consumption good units) exceeds its fundamental value: $q_{0} / p_{0}>F V_{0}$.

A particular case of our productive asset is when every agents share the same and linear technology. In this case, one unit purchased at each date delivers an exogenous amount of consumption good (a real dividend) at the next date. This asset is studied by Tirole (1982), Kocherlakota (1992) and Santos and Woodford (1997). The definition of fundamental value of the asset with exogenous dividends is just the sum (over time) of discounted values of dividends. When dividends are nil, the fundamental value of the asset is zero; this zerodividend asset is studied by Tirole (1985) in OLG frameworks and by Aoki et al. (2014), Hirano and Yanagawa (2013) in infinite-horizon models.

Revisiting the notion of discounting, we introduce a new concept of bubble based on individual preferences. Formally, an $i$ - bubble rests on the individual asset-pricing equation:

$$
\frac{q_{t}}{p_{t}}=\gamma_{i, t+1}\left(\frac{q_{t+1}}{p_{t+1}}+d_{i, t+1}\right)
$$

where $\gamma_{i, t+1}$ is the endogenous discount factor of agent $i$ from date $t$ to date $t+1$, and $d_{i, t+1}$ is her individual dividend at date $t+1$. In this case, the individual fundamental value of land expected by agent $i$ is $F V_{i}:=\sum_{t=1}^{\infty} Q_{i, t} d_{i, t}$ where $Q_{i, t}:=\gamma_{i, 1} \cdots \gamma_{i, t}$. As above, an $i$ - bubble exists if $q_{0} / p_{0}>F V_{i}$. We also say that strong bubble exists if $q_{0} / p_{0}>\max _{i} F V_{i}$ meaning that the land price is strictly higher than every individual fundamental value.

From these definitions, number of results come. First, there exists an agent $i$ such that her expected fundamental value of land equals its equilibrium price: $F V_{i}=q_{0} / p_{0}$, that is, the $i$ - bubble is ruled out. Indeed, when an agent expects a fundamental value of land less than its price, she does not buy land in the long run. At equilibrium, this is not the case for any agent, otherwise the land market clearing condition fails. Most importantly, this result implies the impossibility of strong bubbles, i.e. $q_{0} / p_{0}=\max _{i} F V_{i}$. Second, the ratio $Q_{t} / Q_{i, t}$ is uniformly bounded from above for any $i$, then, there is no room for land bubbles. In 
particular, if the agents' discount factors are identical, bubbles are ruled out; by the way, we recover Le Van and Pham (2014). Third, the agents' expected fundamental values are not less than the fundamental value of land. Moreover, when any individual value of land coincides with its fundamental value, both bubbles and $i$ - bubbles are ruled out. To illustrate this theory and the occurrence of land bubbles, we give an example where endowments fluctuate and agents' TFPs converge to zero. Indeed, agents concerned by a drop in endowments tomorrow buy land today at a higher price in order to smooth their consumption over time. This price is independent on their technologies. We show that when the agent's TFP goes to zero, the fundamental value of land tends to zero as well. By consequence, land bubbles arise.

While land assets and bubbles are valued on the production side, other assets and bubbles may be valued on the consumption side. In the second part of the article, we focus on a leading example: the housing bubbles. Houses are goods that yield utility. An agent buys a house today to enjoy its services, and may resell it tomorrow. Thus, differently from land, the house enters the utility function of its owner. Its marginal utility represents a sort of housing dividend. Most of the results for land bubbles still hold for housing bubbles. A constructive example complements the theory: as above, fluctuations in agents' endowments jointly with a housing preference rate which tends to zero, promote a bubbly equilibrium.

Our paper contribute to the existing literature on asset price bubble, in particular on bubbles of assets delivering endogenous dividends. ${ }^{1}$ Among others, two approaches deserve mention.

(1) Miao and Wang $(2012,2015)$ consider bubbles of firm values with endogenous dividends. They divide in two parts the value $V(K)$ of a firm endowed with $K$ units of initial capital: $V(K)=Q K+B$, where $Q$ represents an endogenous Tobin's $Q$ (marginal). They interpret $Q K$ and $B$ as fundamental value (of the firm) and bubble, respectively.

(2) Becker et al. (2015) introduce instead the concept of physical capital bubble. In this case, the fundamental value of physical capital is the sum of discounted values of capital returns (after depreciation) and physical capital bubbles occurs when the equilibrium price of physical capital exceeds this fundamental value. In our model, land behaves as physical capital and is used to produce a consumption good. However, in Becker et al. (2015), the good is produced by a representative firm, while, in our model, any agent can be viewed as a producer and, therefore, there are as many producers as agents.

Bosi et al (2015a) introduce concepts of bubbles in aggregate and capital goods. They then show how these two kinds of goods generate different bubbles: a bubble in aggregate good may exist even if (1) the present value of output is finite, (2) all consumers are identical, (3) borrowing constraints of consumers are never binding. By contrast, bubbles in capital good $^{2}$ are ruled out if one of three conditions is violated.

The rest of the paper is organized as follows. Section 2 introduces the model and provides some preliminary equilibrium properties. Sections 3 and 4 study land and housing bubbles respectively. Section 5 presents an alternative unified model. Section 6 concludes. All the formal proofs are gathered in Appendices 7 and 8.

\footnotetext{
${ }^{1}$ The reader is referred to Miao (2014) for an introduction to bubbles in infinite-horizon models. Brunnermeier and Oehmke (2012) is a good survey on bubbles in OLG models with asymmetric information or heterogeneous belief.

${ }^{2} \mathrm{~A}$ particular case of bubbles in capital good is that of bubbles in asset with exogenous dividends as in Kocherlakota (1992), Santos and Woodford (1997), Huang and Werner (2000) and Le Van and Pham (2014).
} 


\section{Fundamentals and equilibrium existence}

We consider a discrete-time general equilibrium model without uncertainty. The economy starts at time $t=0$ and goes on forever. There are two markets, one for consumption good and the other for land. A set $I$ of $m$ infinite-lived heterogeneous agents own the land, produce, exchange and consume.

Consumption good. At any date $t$, the $i$ th agent is endowed with $e_{i, t}$ of consumption good. Facing a price $p_{t}$, she decides to consume $c_{i, t}$ units of this good.

Land. The aggregate endowment of land is constant over time and equal to $L$. At the date $t$, the $i$ th agent buys $l_{i, t+1}$ units of land at a price $q_{t}$ in order to produce $F_{i, t}\left(l_{i, t+1}\right)$ units of consumption good. Technology is non-stationary and $F_{i, t}$ is a time-dependent agentspecific production function. When the production is over, the same agent may resell this amount of land at a price $q_{t+1}$. Land allows agents to transfer their wealth over time.

At date 0 , taking the sequence of prices $(p, q)=\left(p_{t}, q_{t}\right)_{t=0}^{\infty}$ as given, the infinite-lived agent chooses the sequence of consumption and land $\left(c_{i}, l_{i}\right):=\left(c_{i, t}, l_{i, t+1}\right)_{t=0}^{\infty}$ to maximize her intertemporal utility. The program writes:

$$
\begin{aligned}
P_{i}(p, q): & \max \sum_{t=0}^{\infty} \beta_{i}^{t} u_{i}\left(c_{i, t}\right) \\
\text { subject to : } & l_{i, t+1} \geq 0 \\
& p_{t} c_{i, t}+q_{t} l_{i, t+1} \leq p_{t} e_{i, t}+q_{t} l_{i, t}+p_{t} F_{i, t}\left(l_{i, t}\right)
\end{aligned}
$$

for any $t \geq 0$. The initial endowment of land $l_{i, 0}>0$ is given.

There are no financial markets. This assumption prevents agents from borrowing.

Definition 1. A sequence of prices and quantities $\left(\bar{p}_{t}, \bar{q}_{t},\left(\bar{c}_{i, t}, \bar{l}_{i, t+1}\right)_{i=1}^{m}\right)_{t=0}^{\infty}$ is an equilibrium of the economy without financial market if the following conditions are satisfied.

(i) Price positivity: $\bar{p}_{t}, \bar{q}_{t}>0$ for any $t \geq 0$.

(ii) Market clearing conditions:

$$
\sum_{i=1}^{m} \bar{c}_{i, t}=\sum_{i=1}^{m}\left[e_{i, t}+F_{i, t}\left(\bar{l}_{i, t}\right)\right] \text { and } \sum_{i=1}^{m} \bar{l}_{i, t}=L
$$

for any $t$.

(iii) Agents' optimality: $\left(\bar{c}_{i, t}, \bar{l}_{i, t+1}\right)_{t=0}^{\infty}$ is a solution of the problem $P_{i}(\bar{p}, \bar{q})$ for any $i$.

In the sequel, we denote for simplicity the equilibrium sequence by $\left(p, q,\left(c_{i}, l_{i}\right)_{i=1}^{m}\right)$. The economy, denoted by $\mathcal{E}$, is identified by a list of fundamentals: $\mathcal{E}:=\left(F_{i}, u_{i}, \beta_{i}, e_{i}, l_{i, 0}\right)$.

As seen above, unavailability of financial assets prevents agents from borrowing. Other authors allow agents to borrow: Bosi et al. (2015b) is an example of economy with land bubbles where imperfect financial markets take place.

If $F_{i}(x)=\xi_{t} x$ for every $i$, where $\left(\xi_{t}\right)$ is an exogenous sequence of returns, land becomes an asset as in Kocherlakota (1992), Santos and Woodford (1997) and Huang and Werner (2000), or looks like a Lucas' tree. If $F_{i}=0$ for every $i$, land becomes a pure bubble as in Tirole (1985). In this case, the fundamental value is zero.

The existence of a competitive equilibrium is ensured by some mild assumptions on technology and preferences, namely the positivity of endowments, the concavity of production and utility functions, and the boundedness of intertemporal utility in the set of feasible consumption sequences. 
Assumption 1. For any $i$ and $t$, the function $F_{i, t}$ is concave and continuously differentiable with $F_{i, t}(0)=0$ and $F_{i, t}^{\prime}>0$.

Assumption 2. $l_{i, 0}>0$ for any $i$ and $e_{i, t}>0$ for any $i$ and $t$.

Assumption 3. For any $i$, the function $u_{i}$ is continuously differentiable and concave with $u_{i}^{\prime}(0)=\infty$ and $u_{i}^{\prime}(x)>0$ if $x>0$.

Assumption 4. $\sum_{t=0}^{\infty} \beta_{i}^{t} u_{i}\left(W_{t}\right)<\infty$ for any $i$, where $W_{t}:=\sum_{i=1}^{m}\left[e_{i, t}+F_{i, t}(L)\right]$ is the maximum amount of consumption available at time $t$.

A standard proof of equilibrium existence is given in Appendix 8.

Proposition 1. Under Assumptions 1 to 4, there exists an equilibrium for the economy $\mathcal{E}$.

\section{Land bubbles}

The definition of bubble rests on the notion of fundamental value which depends on discounting in turn. The first-order conditions of programs $P_{i}(p, q)$ allow us to define the equilibrium discount factors as follows.

Let $\left(p, q,\left(c_{i}, l_{i}\right)_{i=1}^{m}\right)$ be an equilibrium for the economy $\mathcal{E}$. Denote by $\lambda_{i, t}$ and $\mu_{i, t+1}$ the $i$ th agent's multipliers with respect to the budget constraint and the borrowing constraint $l_{i, t+1} \geq 0$, respectively. The first-order conditions write:

$$
\begin{aligned}
\beta_{i}^{t} u_{i}^{\prime}\left(c_{i, t}\right) & =\lambda_{i, t} p_{t} \\
\lambda_{i, t} q_{t} & =\lambda_{i, t+1}\left[q_{t+1}+p_{t+1} F_{i, t+1}^{\prime}\left(l_{i, t+1}\right)\right]+\mu_{i, t+1}
\end{aligned}
$$

jointly with the slackness condition $\mu_{i, t+1} l_{i, t+1}=0$.

Asset pricing rests on no-arbitrage conditions:

$$
\frac{q_{t}}{p_{t}}=\frac{\beta_{i} u_{i}^{\prime}\left(c_{i, t+1}\right)}{u_{i}^{\prime}\left(c_{i, t}\right)}\left[\frac{q_{t+1}}{p_{t+1}}+F_{i, t+1}^{\prime}\left(l_{i, t+1}\right)+\frac{\mu_{i, t+1}}{\lambda_{i, t+1} p_{t+1}}\right]
$$

We introduce the discount factors for individuals and economy.

$$
\gamma_{i, t+1}:=\frac{\beta_{i} u_{i}^{\prime}\left(c_{i, t+1}\right)}{u_{i}^{\prime}\left(c_{i, t}\right)} \text { and } \gamma_{t+1}:=\max _{i \in I} \frac{\beta_{i} u_{i}^{\prime}\left(c_{i, t+1}\right)}{u_{i}^{\prime}\left(c_{i, t}\right)}
$$

are, respectively, the individual discount factor and the discount factor of the economy from date $t$ to date $t+1$. We then define the individual discount factor and the discount factor of the economy from date 0 to date $t$ :

$$
Q_{i, t}:=\gamma_{i, 1} \ldots \gamma_{i, t} \text { and } Q_{t}:=\gamma_{1} \ldots \gamma_{t}
$$

with $Q_{i, 0}:=Q_{0}:=1$.

We now define the lowest and the highest productivities:

$$
\underline{d}_{t}:=\min _{i \in I} F_{i, t}^{\prime}\left(l_{i, t}\right) \text { and } \bar{d}_{t}:=\max _{i \in I} F_{i, t}^{\prime}\left(l_{i, t}\right)
$$




\subsection{Fundamental value of land and land bubbles}

Asset pricing and productivity bounds are closely related through condition (3).

Lemma 1. The relative price of land is bounded as follows:

$$
\gamma_{t+1}\left(\frac{q_{t+1}}{p_{t+1}}+\underline{d}_{t+1}\right) \leq \frac{q_{t}}{p_{t}} \leq \gamma_{t+1}\left(\frac{q_{t+1}}{p_{t+1}}+\bar{d}_{t+1}\right)
$$

The introduction of land dividends allows us to define the land bubbles.

Definition 2 (dividends of land). A land dividend $d_{t+1}$ at date $t+1$ satisfies a no-arbitrage equation:

$$
\frac{q_{t}}{p_{t}}=\gamma_{t+1}\left(\frac{q_{t+1}}{p_{t+1}}+d_{t+1}\right)
$$

The value of a unit of land today in terms of consumption good equals the discounted value of the reselling relative price tomorrow and the amount of consumption good delivered by the unit. Because of condition (5), dividends become endogenous. The role of land is captured by the sequence of dividends at the end and equation (5) can be viewed either as an asset-pricing or a non-arbitrage condition.

Inequalities (4) entail that any land dividend is bounded by the lowest and the highest marginal productivities: $d_{t} \in\left[\underline{d}_{t}, \bar{d}_{t}\right]$.

Since $Q_{t+1}=\gamma_{t+1} Q_{t},(5)$ writes

$$
Q_{t} \frac{q_{t}}{p_{t}}=Q_{t+1}\left(\frac{q_{t+1}}{p_{t+1}}+d_{t+1}\right)
$$

Solving forward, we find an intertemporal asset-pricing equation

$$
\frac{q_{0}}{p_{0}}=\sum_{t=1}^{T} Q_{t} d_{t}+Q_{T} \frac{q_{T}}{p_{T}}
$$

which holds for any $T \geq 1$. This fundamental equation allows us to introduce the notion of land bubble.

Definition 3 (land bubble). The fundamental value of land is given by $F V_{0}:=\sum_{t=1}^{\infty} Q_{t} d_{t}$. $A$ land bubble exists if the relative price of land (in terms of consumption good) strictly exceeds the fundamental value: $q_{0} / p_{0}>F V_{0}$.

Here the price of land $q_{0} / p_{0}$ is decomposed into two parts: the fundamental value $F V_{0}$ and the bubble term $\lim _{t \rightarrow \infty}\left(Q_{t} q_{t} / p_{t}\right)$ which can be viewed as the reselling price of one unit of land at the infinity.

\subsubsection{General results}

In the spirit of Montrucchio (2004), Le Van and Pham (2014), we provide a simple characterization of bubble existence.

Proposition 2. The following statements are equivalent.

(i) Land bubbles exist.

(ii) $\lim _{t \rightarrow \infty}\left(Q_{t} q_{t} / p_{t}\right)>0$. 
(iii) $\sum_{t=1}^{\infty}\left(p_{t} d_{t} / q_{t}\right)<\infty$.

Note that this result only requires the asset pricing equation (2). Proposition 2 holds for any form of production functions, including non-stationary technologies.

Let us consider a particular case where technologies are stationary $\left(F_{i, t}=F_{i}\right.$ for every $i$ and $t$ ). In this case, we have $d_{t} \geq \min _{i} F_{i}^{\prime}\left(l_{i, t}\right) \geq \min _{i} F_{i}^{\prime}(L)>0$ for every $t$ and, by consequence, condition (iii) in Proposition 2 simplifies.

Corollary 1. If technologies are stationary and a land bubble exists, then $\sum_{t=1}^{\infty}\left(p_{t} / q_{t}\right)<\infty$.

In other terms, the existence of land bubbles implies that the relative price of land $q_{t} / p_{t}$ tends to infinity. However, this property only holds under stationary technologies. We will readdress this issue in Section 3.2 through an explicit example.

The transversality condition simplifies under our definition of individual discounting.

Lemma 2 (transversality condition). $\lim _{t \rightarrow \infty}\left(Q_{i, t} l_{i, t+1} q_{t} / p_{t}\right)=0$ for any $i$.

The structure of discount factors plays also a role in the existence of bubbles.

Proposition 3. If, for any $i$, the ratio $Q_{t} / Q_{i, t}$ is uniformly bounded from above, then there is no bubble.

By consequence, a land bubble may arise only if the endogenous discount factors $Q_{i, t}$ are different at infinitely many dates. In more standard models of rational bubbles with exogenous dividends such as Kocherlakota (1992), Huang and Werner (2000), Le Van and Pham (2014), the heterogeneity of endogenous discount factors vanishes if agents' borrowing constraints are no longer binding.

In our paper, the properties of production functions $F_{i, t}$ plays also an important role in the heterogeneity of discount factors. Let agents share the same linear technology, that is $F_{i, t}(X)=\xi_{t} X$ for any $i$ and $t$ (Lucas' tree). In this case, If $l_{i, t}>0$ for any $i$ and $t$, the discount factors turn out to be the same and bubbles are ruled out.

Remark 1. In general, the discount factors may differ even if $l_{i, t}>0$ for any $i$ and $t$. Indeed, consider the case where every agent has the same production function but non-linear: $F_{i}(x)=A x^{\alpha}$ with $\alpha \in(0,1)$. At equilibrium, we have $l_{i, t}>0$ for any $i$ and $t$, but the marginal productivities $A l_{i, t}^{\alpha-1}$ and $A l_{j, t}^{\alpha-1}$ may be different. This is because of the absence of financial markets (no agent can borrow).

\subsubsection{New concepts of bubbles}

The first-order conditions imply

$$
\frac{q_{t}}{p_{t}}=\gamma_{i, t+1}\left(\frac{q_{t+1}}{p_{t+1}}+d_{i, t+1}\right)
$$

where $d_{i, t+1}:=F_{i, t+1}^{\prime}\left(l_{i, t+1}\right)+\mu_{i, t+1} /\left(\lambda_{i, t+1} p_{t+1}\right)$ can be interpreted as an individual land dividend for agent $i$ at date $t+1$. Since the individual discount factor $\gamma_{i, t+1}$ is less than the factor of the economy $\gamma_{t+1}$, the individual dividend $d_{i, t+1}$ expected by agent $i$ is greater than the dividend $d_{t+1}$ of the economy. Moreover, $\min _{i} d_{i, t+1}=d_{t+1}$.

If we write $\gamma_{i, t+1}=1 /\left(1+r_{i, t+1}\right)$ where $r_{i, t+1}$ is the expected interest rate by the $i$ th agent at the date $t+1$, then the asset-pricing equation (7) becomes

$$
\frac{q_{t}}{p_{t}}\left(1+r_{i, t+1}\right)=\frac{q_{t+1}}{p_{t+1}}+d_{i, t+1}
$$


In other words, the relative price of land at date $t$ and its interests equals the sum of the same price at date $t+1$ and individual land dividends.

The asset-pricing equation (7) shows how the $i$ th agent evaluates the price of land. This agent buys land today and resells it tomorrow at the price $q_{t+1}$ after earning $d_{i, t+1}$ units of consumption good as dividend. She compares the current price with the future gains discounted at the rate $\gamma_{i, t+1}$.

Solving recursively (7), we can separate the land price in two parts.

$$
\frac{q_{0}}{p_{0}}=\sum_{t=1}^{T} Q_{i, t} d_{i, t}+Q_{i, T} \frac{q_{T}}{p_{T}}
$$

(8) leads us to define new concepts of bubbles.

Definition 4 ( $i$ - bubble). The individual value of land with respect to agent $i$ is $F V_{i}:=$ $\sum_{t=1}^{\infty} Q_{i, t} d_{i, t}$. We say that an $i$ - bubble exists if $q_{0} / p_{0}>F V_{i}$.

Our concept of $i$ - bubble is closely related to that of bubbles of durable goods and collateralized assets considered by Araujo et al. (2011). In their terminology, factors $Q_{i, t}$ are called deflators and multipliers $\mu_{i, t}$ are called non-pecuniary returns.

We apply the same arguments of Proposition 2.

Proposition 4. The following statements are equivalent.

(i) $i$ - bubbles exist.

(ii) $\lim _{t \rightarrow \infty}\left(Q_{i, t} q_{t} / p_{t}\right)>0$.

(iii) $\sum_{t=1}^{\infty}\left(p_{t} d_{i, t} / q_{t}\right)<\infty$.

By combining point (ii) of Proposition 4 and Lemma 2 we have the following result.

Lemma 3. If an $i$ - bubble exists, then $\lim _{t \rightarrow \infty} l_{i, t}=0$.

In other words, when an agent expects a fundamental value of land strictly less than its price, she does not buy land in the long run. At equilibrium the land market clears $\sum_{i=1}^{m} l_{i, t}=L$. As a consequence, Lemma 3 implies that there exists an agent $i$ such that the individual value of land expected by this agent is equal to the equilibrium price of land.

Proposition 5. There exists an agent $i$ such that an $i$-bubble is ruled out.

Now, let us bridge the two concepts of bubble and $i$ - bubble.

Proposition 6. 1. If an $i$ - land bubble exists for some agent $i$, then land bubbles exist as well.

2. $F V_{0} \leq F V_{i}$ for any $i$. Moreover, if $F V_{0}=F V_{i}$ for any $i$, then $F V_{0}=F V_{i}=q_{0} / p_{0}$ for any $i$ : there are neither bubbles nor $i$ - bubbles.

Note that the converse of point 1 is not true. ${ }^{3}$ Point 2 of Proposition 6 is highly intuitive. Since any agent expects an interest rate which is higher than that of economy, the individual value of land expected by any agent will be higher than the fundamental value of land. Interestingly, when any individual value of land coincides with that of economy, both bubble and individual bubbles are ruled out. However when any individual value of land is identical but different from the fundamental value of land, we do not know whether land bubbles are ruled out. ${ }^{4}$

\footnotetext{
${ }^{3}$ See the example in Section 3.2.

${ }^{4}$ See Remark 4.
} 
Remark 2. Let $B_{0}:=q_{0} / p_{0}-F V_{0}$ and $B_{i}:=q_{0} / p_{0}-F V_{i}$ denote the bubble and $i$ - bubble respectively. We observe that $B_{i} \leq B_{0}$ for every $i$.

Another concept of bubble, more restrictive, rests also on the notions of individual fundamental values.

Definition 5 (strong bubble). We say that a strong bubble exists if the asset price exceeds any individual value of land, that is $q_{0} / p_{0}>\max _{i \in I} F V_{i}$

The following result is a direct consequence of Proposition 4.

Proposition 7. The following statements are equivalent.

(i) A strong bubble exists.

(ii) $\min _{i \in I} \lim _{t \rightarrow \infty}\left(Q_{i, t} q_{t} / p_{t}\right)>0$.

(iii) $\max _{i \in I} \sum_{t=1}^{\infty}\left(p_{t} d_{i, t} / q_{t}\right)<\infty$.

The existence of a strong land bubble entails the existence of an $i$ - bubble for any $i$. Nevertheless, Proposition 5 prevents from this possibility and implies a new straightforward result.

Proposition 8. Strong land bubbles never occur in our model because $q_{0} / p_{0}=\max _{i \in I} F V_{i}$.

Remark 3. Strong bubbles are ruled out in our framework because of the transversality conditions: $\lim _{t \rightarrow \infty}\left(Q_{i, t} l_{i, t+1} q_{t} / p_{t}\right)=0$ for any $i$. However, in more general frameworks (for example, when uncertainty takes place as in Araujo et al. (2011) or Araujo et al. (2011)), the alternative transversality conditions are quite different and it is not trivial to prove them.

Our concept of strong bubble is related to the notion of speculative bubble in Werner (2014). He considers an asset bringing exogenous dividends in a model with ambiguity and defines a fundamental value based on agent's beliefs as the sum of discounted expected future dividends weighted by these beliefs. Then, he says that a speculative bubble exists if the asset price strictly exceeds any agent's fundamental value.

The readers may wonder why there is room for speculative bubbles à la Werner (2014) but not for strong bubbles in infinite-horizon models. It is hard to compare these two results within different frameworks (with and without ambiguity). The linearity of utility functions also matters. We impose Inada condition for utility functions to ensure a strictly positive individual consumption at equilibrium while Werner (2014) works with linear preferences. With linear utility functions, a simple non-negativity constraint on consumption $c_{i, t} \geq 0$ may be binding. In this case, condition (2) no longer holds and the ratio $p_{t+1} \lambda_{i, t+1} /\left(p_{t} \lambda_{i, t}\right)$ may become higher than the marginal rate of substitution $\beta_{i}=\beta_{i} u_{i}^{\prime}\left(c_{i, t+1}\right) / u_{i}^{\prime}\left(c_{i, t}\right)$. By consequence, the asset price $q_{0} / p_{0}$ may exceed $\sum_{t=1}^{\infty} \beta_{i}^{t} d_{i, t}$, the fundamental value with respect to the ith agent and strong bubbles may exist at the end.

From a theoretical point of view, the existence of bubbles depends on how we define the fundamental value of an asset, a somewhat ambiguous concept.

\subsection{Example of land bubbles}

We consider non-stationary production functions and we provide a constructive example of bubbly equilibrium. For simplicity, we normalize the price of consumption good to one: $p_{t}=1$ for any $t$. Focus on an oversimplified economy with two agents $A$ and $B$ and linear 
technologies: $F_{A, t}(L)=A_{t} L$ and $F_{B, t}(L)=B_{t} L$. Preferences are rationalized by a common logarithmic utility function: $u_{A}(x)=u_{B}(x):=\ln (x)$. Finally, agents' endowments are supposed to be zero any two periods: $e_{A, 2 t}=e_{B, 2 t+1}=0$ for any $t$, and the supply of land inelastic: $L=1$.

We need the following conditions to verify the first-order conditions and to identify the discount factors of the economy $\left(\gamma_{t}\right) .{ }^{5}$

$$
\begin{aligned}
& \beta_{A}\left(A_{2 t}+\frac{\beta_{B} e_{B, 2 t}}{1+\beta_{B}}\right)\left(A_{2 t+1}+\frac{\beta_{A} e_{A, 2 t+1}}{1+\beta_{A}}\right) \leq \beta_{B} \frac{e_{B, 2 t}}{1+\beta_{B}} \frac{e_{A, 2 t+1}}{1+\beta_{A}} \\
& \beta_{B}\left(B_{2 t}+\frac{\beta_{B} e_{B, 2 t}}{1+\beta}\right)\left(B_{2 t-1}+\frac{\beta_{A} e_{A, 2 t-1}}{1+\beta_{A}}\right) \leq \beta_{A} \frac{e_{B, 2 t}}{1+\beta_{B}} \frac{e_{A, 2 t-1}}{1+\beta_{A}} \\
& \beta_{A}\left(A_{2 t}+\frac{\beta_{B} e_{B, 2 t}}{1+\beta_{B}}\right)\left(B_{2 t+1}+\frac{\beta_{A} e_{A, 2 t+1}}{1+\beta_{A}}\right) \leq \beta_{B} \frac{e_{B, 2 t}}{1+\beta_{B}} \frac{e_{A, 2 t+1}}{1+\beta_{A}} \\
& \beta_{B}\left(A_{2 t}+\frac{\beta_{B} e_{B, 2 t}}{1+\beta}\right)\left(B_{2 t-1}+\frac{\beta_{A} e_{A, 2 t-1}}{1+\beta_{A}}\right) \leq \beta_{A} \frac{e_{B, 2 t}}{1+\beta_{B}} \frac{e_{A, 2 t-1}}{1+\beta_{A}}
\end{aligned}
$$

We will check in Appendix that the sequence of allocations

$$
\begin{aligned}
\left(c_{A, 2 t}, c_{B, 2 t}\right) & =\left(q_{2 t}+A_{2 t}, e_{B, 2 t}-q_{2 t}\right) \\
\left(c_{A, 2 t+1}, c_{B, 2 t+1}\right) & =\left(e_{A, 2 t+1}-q_{2 t+1}, q_{2 t+1}+B_{2 t+1}\right) \\
\left(l_{A, 2 t}, l_{B, 2 t}\right) & =(1,0) \\
\left(l_{A, 2 t+1}, l_{B, 2 t+1}\right) & =(0,1)
\end{aligned}
$$

and land prices

$$
q_{2 t}=\frac{\beta_{B}}{1+\beta_{B}} e_{B, 2 t} \text { and } q_{2 t+1}=\frac{\beta_{A}}{1+\beta_{A}} e_{A, 2 t+1}
$$

form a general equilibrium $\left(p_{t}, q_{t},\left(c_{i, t}, l_{i, t+1}\right)_{i \in I}\right)_{t}$.

The sequence of discount factors is computed:

$$
\gamma_{2 t}=\frac{\beta_{A} u_{A}^{\prime}\left(c_{A, 2 t}\right)}{u_{A}^{\prime}\left(c_{A, 2 t-1}\right)} \text { and } \gamma_{2 t+1}=\frac{\beta_{B} u_{B}^{\prime}\left(c_{B, 2 t+1}\right)}{u_{B}^{\prime}\left(c_{B, 2 t}\right)}
$$

It allows us to compute in turn the sequence of dividends:

$$
d_{2 t}=A_{2 t}, \quad d_{2 t+1}=B_{2 t+1}
$$

and to write eventually an explicit characterization of bubble existence. Indeed, according to Proposition 2, land bubbles exist if and only if

$$
\sum_{t=0}^{\infty} \frac{d_{t}}{q_{t}}=\sum_{t=0}^{\infty} \frac{A_{2 t}}{e_{B, 2 t}}+\sum_{t=0}^{\infty} \frac{B_{2 t+1}}{e_{A, 2 t+1}}<\infty
$$

In other words, the existence of bubbles requires "low" dividends.

The intuition is straightforward. In the odd periods $(2 t+1)$, agent $B$ has no endowments. She wants to smooth consumption over time according to her logarithm utility (which satisfies the Inada conditions), but she can not transfer her wealth from future to this date because of the borrowing constraint. As a consequence, she accepts to buy land at date $2 t$ at a higher price: $q_{2 t} \geq e_{B, 2 t} \beta_{B} /\left(1+\beta_{B}\right)$, independent on agents' productivity. A lower productivity implies lower dividends and a lower fundamental value of land. As long as dividends tend to zero, the land price remains higher than this fundamental value.

Let us revisit the characterization of bubble existence under stationary technologies.

\footnotetext{
${ }^{5}$ These conditions are satisfied if, for instance, $\beta_{A}=\beta_{B}:=\beta, A_{2 t}, B_{2 t}<e_{B, 2 t}(1-\beta) /(1+\beta)$ and $A_{2 t+1}, B_{2 t+1}<e_{A, 2 t+1}(1-\beta) /(1+\beta)$ for any $t$.
} 
Corollary 2. Assume that $A_{t}=A>0$ and $B_{t}=B>0$ for any $t$. Then, land bubbles exist if and only if

$$
\sum_{t=0}^{\infty}\left(\frac{1}{e_{B, 2 t}}+\frac{1}{e_{A, 2 t+1}}\right)<\infty
$$

In this example, land bubbles exist if and only if $\sum_{t=1}^{\infty} 1 / q_{t}<\infty$. This elegant characterization also illustrates Corollary 1.

Corollary 3. Assume that $e_{A, 2 t+1}=e_{B, 2 t}=e>0$ for any $t$. Then, land bubbles exist if and only if

$$
\sum_{t=0}^{\infty}\left(A_{2 t}+B_{2 t+1}\right)<\infty
$$

This result is consistent with the example in Bosi et al (2015a) where bubbles in capital good arise if the sum of capital good returns is finite.

Remark 4 (bubble vs $i$ - bubble). Since $\lim _{t \rightarrow \infty}\left[\beta_{i}^{t} u_{i}^{\prime}\left(c_{i, t}\right) q_{t}\right]=0$ for $i=A, B$, there are no $i$ - bubbles. However, a land bubble may occur. In this case, any individual value of land is identical and equals to the equilibrium price but may be strictly higher that the fundamental value of land.

\section{Land bubbles and prices}

Corollary 1 points out a necessary condition for land bubbles under stationary technologies: land prices must diverge to infinity. In our example, technologies are non-stationary and the land prices are given by (13). Thus, a land bubble may exist with asset prices either increasing or decreasing or fluctuating over time. In this respect, we recover and generalize Weil (1990), an example of bubble with decreasing asset prices. Indeed, his model is a particular case with $A_{t}=B_{t}=0$ for any $t \geq T$ (land will give no fruits from some date on).

\section{Pure bubbles}

If $A_{t}=B_{t}=0$ for any $t$, the fundamental value of land is zero. In this case, a sequence of positive prices ( $q_{t}>0$ for any $\left.t\right)$ is called a pure (land) bubble. It is easy to see that our example admits an equilibrium with pure bubbles.

Remark 5. In this example, although agents have linear production functions, these functions are different.

There is a case where the productivity of agent $A$ is higher than that of agent $B$, i.e., $A_{2 t+1}>B_{2 t+1}$, but agent $A$ does not produce at date $2 t+1$. For two reasons: (1) agents are prevented from borrowing, (2) agents' endowments change over time. Although $A$ has a higher productivity at date $2 t+1$, she has also a higher endowment at this date, but no endowment at date $2 t$. So, she may not need to buy land at date $2 t$ to produce and transfer wealth from date $2 t$ to date $2 t+1$. Instead, she sells land at date $2 t$ to buy and consume consumption good at date $2 t$. Therefore, agent $A$ may not produce at date $2 t+1$ even if $A_{2 t+1}>B_{2 t+1}$.

\subsection{Example of individual land bubbles}

Fundamentals of the economy. Consider the example in Section 3.2. For the sake of simplicity, we assume that $\beta_{A}=\beta_{B}=: \beta$. 
We add the third agent: agent $D$. The utility, the rate of time preference, and the technologies of agent $D$ are

$$
u_{D}(c)=\ln (c), \quad \beta_{D}=\beta, \quad F_{D, t}(L)=D_{t} L
$$

The endowments $\left(e_{D, t}\right)_{t}$ and productivities $\left(D_{t}\right)$ of agents $D$ are defined by

$$
\frac{\beta e_{D, t}}{e_{D, t+1}}=\frac{q_{t}}{q_{t+1}+D_{t+1}}=\gamma_{t+1}
$$

where $\left(\gamma_{t}\right)$ is determined as in Section 3.2. We see that such sequences $\left(e_{D, t}\right)_{t}$ and $\left(D_{t}\right)$ exist. Indeed, for example, we choose $D_{t}=d_{t}$ where $d_{t}$ is determined as in (14). Then, we choose $\left(e_{D, t}\right)_{t}$ such that $\beta e_{D, t}=\gamma_{t+1} e_{D, t+1}$.

Equilibrium: Prices and allocations of agents $A$ and $B$ are as in Section 3.2. The allocations of agent $D$ are $c_{D, t}=e_{D, t}$ and $l_{D, t}=0$ for any $t$. By using the same argument in Section 3.2 , it is easy to verify that this system of prices and allocations constitutes an equilibrium.

We observe that agent $D$ does not trade and $\gamma_{D, t}=\beta e_{D, t-1} / e_{D, t}=\gamma_{t}$ for any $t$. By consequence, $\lim _{t \rightarrow \infty} Q_{D, t} q_{t}=\lim _{t \rightarrow \infty} Q_{t} q_{t}>0$. There is a $D$ - bubble, i.e. the equilibrium price of land is strictly higher than the individual value of land with respect to agent $D$.

Remark 6. In the spirit of this example, we may provide other examples of bubbles with other production functions, for example $F_{i, t}(x)=a_{i, t} l n(1+x)$ where $a_{i, t}>0$.

\section{Housing bubbles}

Houses are different kind of assets. While land is a production factor, houses are consumption goods. While the former is valued through the production function, the latter are priced through a consumption demand. To formalize and understand asset pricing and bubbles in the case of a housing market, we consider a simple two-good economy with consumption and housing whose prices are $p_{t}$ and $q_{t}$ at date $t$ respectively. Household $i$ is endowed with $h_{i, 0}$ houses at the initial date and $e_{i, t}$ units of consumption good at any date $t$. For simplicity, we consider a separable utility function: $u_{i}\left(c_{i, t}\right)+v_{i, t}\left(h_{i, t}\right)$ where $u_{i}$ is the consumption utility and $v_{i, t}$ the housing utility function which is assumed to be concave. Without loss of generality, the consumption utility is supposed to be stationary.

Houses are traded every period as follows. The agent $i$ buys $h_{i, t}$ units of house at date $t-1$. At date $t$, she enjoys the house services, that is a utility $v_{i, t}\left(h_{i, t}\right)$, and resells her house at price $q_{t}$. Under the assumption of non-stationary housing utility, we obtain more general results on asset pricing and characterization of bubble.

Taking the sequence of prices $(p, q)=\left(p_{t}, q_{t}\right)_{t=0}^{\infty}$ as given, each household $i$ chooses the sequence of goods $\left(c_{i}, h_{i}\right):=\left(c_{i, t}, h_{i, t}\right)_{t=0}^{\infty}$ and solves a program to maximize her intertemporal utility function:

$$
\begin{aligned}
R_{i}(p, q): & \max \sum_{t=0}^{\infty} \beta_{i}^{t}\left[u_{i}\left(c_{i, t}\right)+v_{i, t}\left(h_{i, t}\right)\right] \\
\text { subject to }: & h_{i, t+1} \geq 0 \\
& p_{t} c_{i, t}+q_{t} h_{i, t+1} \leq p_{t} e_{i, t}+q_{t} h_{i, t}
\end{aligned}
$$

for any $t$.

Definition 6. A list of prices and quantities $\left(\bar{p}_{t}, \bar{q}_{t},\left(\bar{c}_{i, t}, \bar{h}_{i, t+1}\right)_{i=1}^{m}\right)_{t=0}^{\infty}$ is an equilibrium of the economy without financial markets under the following conditions. 
(i) Price positivity: $\bar{p}_{t}, \bar{q}_{t}>0$ for any $t \geq 0$.

(ii) Market clearing conditions: $\sum_{i=1}^{m} \bar{c}_{i, t}=\sum_{i=1}^{m} e_{i, t}$ and $\sum_{i=1}^{m} \bar{h}_{i, t}=H$ for any $t \geq 0$.

(iii) Agents' optimality: for any $i,\left(\bar{c}_{i, t}, \bar{h}_{i, t+1}\right)_{t=0}^{\infty}$ is a solution of program $R_{i}(\bar{p}, \bar{q})$.

In the sequel, we denote for simplicity the equilibrium sequence by $\left(p, q,\left(c_{i}, h_{i}\right)_{i=1}^{m}\right)$. It is easy to prove the existence of reduced multipliers $\nu_{i, t+1} \geq 0$ such that the slackness condition $\nu_{i, t+1} h_{i, t+1}=0$ and the asset-pricing (no-arbitrage) condition

$$
\frac{q_{t}}{p_{t}}=\frac{\beta_{i} u_{i}^{\prime}\left(c_{i, t+1}\right)}{u_{i}^{\prime}\left(c_{i, t}\right)}\left[\frac{q_{t+1}}{p_{t+1}}+\frac{v_{i, t}^{\prime}\left(h_{i, t+1}\right)}{u_{i}^{\prime}\left(c_{i, t+1}\right)}+\nu_{i, t+1}\right]
$$

hold.

As above, we introduce the transition discount factors (individual and maximal) from time $t$ to time $t+1$ :

$$
\gamma_{i, t+1}:=\frac{\beta_{i} u_{i}^{\prime}\left(c_{i, t+1}\right)}{u_{i}^{\prime}\left(c_{i, t}\right)} \text { and } \gamma_{t+1}:=\max _{i \in I} \frac{\beta_{i} u_{i}^{\prime}\left(c_{i, t+1}\right)}{u_{i}^{\prime}\left(c_{i, t}\right)}
$$

and the corresponding compound discount factors: $Q_{i, t}:=\gamma_{i, 1} \cdots \gamma_{i, t}$ and $Q_{t}:=\gamma_{1} \cdots \gamma_{t}$, with $Q_{i, 0}:=Q_{0}:=1$.

As above, the transversality condition involves quantities and prices.

Lemma 4. $\lim _{t \rightarrow \infty}\left(Q_{i, t} h_{i, t+1} q_{t} / p_{t}\right)=0$ for any $i$.

Similarly to Lemma 1, the lowest and the highest marginal rates of substitution between consumption and housing drive the asset pricing:

$$
\gamma_{t+1}\left(\frac{q_{t+1}}{p_{t+1}}+\underline{d}_{t+1}\right) \leq \frac{q_{t}}{p_{t}} \leq \gamma_{t+1}\left(\frac{q_{t+1}}{p_{t+1}}+\bar{d}_{t+1}\right)
$$

where

$$
\underline{d}_{t+1}:=\min _{i \in I} \frac{v_{i, t+1}^{\prime}\left(h_{i, t+1}\right)}{u_{i}^{\prime}\left(c_{i, t+1}\right)} \text { and } \bar{d}_{t+1}:=\max _{i \in I} \frac{v_{i, t+1}^{\prime}\left(h_{i, t+1}\right)}{u_{i}^{\prime}\left(c_{i, t+1}\right)}
$$

We are naturally leaded to introduce the housing dividend $d_{t}$ and the individual housing dividend $d_{i, t}$ through the asset-pricing equation

$$
\frac{q_{t}}{p_{t}}=\gamma_{t+1}\left(\frac{q_{t+1}}{p_{t+1}}+d_{t+1}\right)
$$

Equivalently, we define the individual housing dividend $d_{i, t}$ of agent $i$ as follows:

$$
d_{i, t+1}:=\frac{v_{i, t+1}^{\prime}\left(h_{i, t+1}\right)}{u_{i}^{\prime}\left(c_{i, t+1}\right)}+\nu_{i, t+1}
$$

\subsection{Fundamental value of housing and housing bubbles}

Land and housing are assets of different nature. Land dividends are determined by the marginal productivities while housing dividends are determined by marginal utilities. By the way, our model of housing is related to the money-in-utility-function model by Tirole (1985). These models differ in two main respects: (1) we study infinite-lived agents instead of overlapping generations and (2) Tirole's utility function depends on money prices.

In the spirit of Section 3, we introduce new concepts of housing bubbles. 
Definition 7 (housing bubble). The fundamental value of a house is defined by $F V_{0}:=$ $\sum_{t=1}^{\infty} Q_{t} d_{t}$. We say that housing bubbles exist if the market price of houses (in term of consumption good) exceeds the fundamental value, that is $q_{0} / p_{0}>F V_{0}$.

Definition 8 (individual housing bubble). The individual value of a house with respect to the agent $i$ is defined by $F V_{i}:=\sum_{t=1}^{\infty} Q_{i, t} d_{i, t}$.

We say that an $i$ - housing bubble exists if $q_{0} / p_{0}>F V_{i}$.

We say that a strong housing bubble exists if $q_{0} / p_{0}>\max _{i} F V_{i}$.

Results of Propositions 2, 3, 4, 5, 6, 7 and 8 also hold for housing bubbles.

\subsection{Example of housing bubbles}

A constructive example illustrates the emergence of housing bubbles. Consider an economy with two agents $A$ and $B$ whose preferences are logarithmic with respect to consumption: $u_{A}(x)=u_{B}(x):=\ln (x)$; non-stationary and linear with respect to housing: $v_{A, t}(h)=A_{t} h$ and $v_{B, t}(h)=B_{t} h$. For simplicity, the supply of houses is inelastic: $H=1$. Endowments fluctuate: for any $t, e_{A, 2 t}=e_{B, 2 t+1}=0$ and $e_{A, 2 t+1}, e_{B, 2 t}>0$. We normalize the consumption prices $\left(p_{t}=1\right.$ for any $\left.t\right)$ and we construct an equilibrium sequence $\left(p_{t}, q_{t},\left(c_{i, t}, h_{i, t+1}\right)_{i \in I}\right)_{t}$. The sequence of equilibrium allocations is given by

$$
\begin{aligned}
\left(c_{A, 2 t}, c_{B, 2 t}\right) & =\left(q_{2 t}, e_{B, 2 t}-q_{2 t}\right) \\
\left(c_{A, 2 t+1}, c_{B, 2 t+1}\right) & =\left(e_{A, 2 t+1}-q_{2 t+1}, q_{2 t+1}\right) \\
\left(h_{A, 2 t}, h_{B, 2 t}\right) & =(1,0) \\
\left(h_{A, 2 t+1}, h_{B, 2 t+1}\right) & =(0,1)
\end{aligned}
$$

with prices:

$$
q_{2 t}=\frac{\beta_{B}\left(1+B_{2 t+1}\right)}{1+\beta_{B}\left(1+B_{2 t+1}\right)} e_{B, 2 t} \text { and } q_{2 t-1}=\frac{\beta_{A}\left(1+A_{2 t}\right)}{1+\beta_{A}\left(1+A_{2 t}\right)} e_{A, 2 t-1}
$$

The first-order conditions rest on two restrictions: $1 \geq \beta_{B} B_{2 t}+\beta_{B}^{2}\left(1+B_{2 t+1}\right)$ and $1 \geq \beta_{A} A_{2 t-1}+\beta_{A}^{2}\left(1+A_{2 t}\right)$. Moreover, inequalities $1 \geq \beta_{A}^{2}\left(1+A_{2 t}\right)\left(1+B_{2 t-1}\right)$ and $1 \geq$ $\beta_{B}^{2}\left(1+A_{2 t}\right)\left(1+B_{2 t+1}\right)$ imply the inequalities $\gamma_{B, 2 t+1} \geq \gamma_{A, 2 t+1}$ and $\gamma_{A, 2 t} \geq \gamma_{B, 2 t}$ under which the above sequence of allocations turns out to be an equilibrium sequence. It is easy to compute the discount factors of the economy

$$
\gamma_{2 t+1}=\frac{\beta_{B} u_{B}^{\prime}\left(c_{B, 2 t+1}\right)}{u_{B}^{\prime}\left(c_{B, 2 t}\right)} \text { and } \gamma_{2 t}=\frac{\beta_{A} u_{A}^{\prime}\left(c_{A, 2 t}\right)}{u_{A}^{\prime}\left(c_{A, 2 t-1}\right)}
$$

as well as the equilibrium dividends: $d_{2 t}=A_{2 t} c_{A, 2 t}$ and $d_{2 t+1}=B_{2 t+1} c_{B, 2 t+1}$.

The characterization of Proposition 2 applies: housing bubbles exist if and only if

$$
\sum_{t=0}^{\infty} \frac{d_{t}}{q_{t}}=\sum_{t=0}^{\infty}\left(A_{2 t}+B_{2 t+1}\right)<\infty
$$

Our example points out the possibility of housing bubble when individual endowments fluctuate over time and the housing preference rates $A_{t}$ and $B_{t}$ converges to zero. 


\section{$5 \quad$ A unified framework}

So far, we see that both the models presented above share a common approach. We may introduce an asset (with fixed supply $G$ ) which is not only used to produce but also gives utility for agents. In this case, taking the sequence of prices $(p, q)=\left(p_{t}, q_{t}\right)_{t=0}^{\infty}$ as given, each household $i$ chooses the sequence of allocations $\left(c_{i}, a_{i}\right):=\left(c_{i, t}, a_{i, t}\right)_{t=0}^{\infty}$ and solves a program to maximize her intertemporal utility function:

$$
\begin{aligned}
S_{i}(p, q): & \max \sum_{t=0}^{\infty} \beta_{i}^{t}\left[u_{i}\left(c_{i, t}\right)+v_{i, t}\left(a_{i, t}\right)\right] \\
\text { subject to : } & a_{i, t+1} \geq 0 \\
& p_{t} c_{i, t}+q_{t} a_{i, t+1} \leq p_{t} e_{i, t}+q_{t} a_{i, t}+p_{t} F_{i, t}\left(a_{i, t}\right)
\end{aligned}
$$

Definition 9. A list of prices and quantities $\left(\bar{p}_{t}, \bar{q}_{t},\left(\bar{c}_{i, t}, \bar{a}_{i, t+1}\right)_{i=1}^{m}\right)_{t=0}^{\infty}$ is an equilibrium of the economy without financial markets under the following conditions.

(i) Price positivity: $\bar{p}_{t}, \bar{q}_{t}>0$ for any $t \geq 0$.

(ii) Market clearing conditions: $\sum_{i=1}^{m} \bar{c}_{i, t}=\sum_{i=1}^{m}\left(e_{i, t}+F_{i, t}\left(\bar{a}_{i, t}\right)\right)$ and $\sum_{i=1}^{m} \bar{a}_{i, t}=G$ for any $t \geq 0$.

(iii) Agents' optimality: for any $i,\left(\bar{c}_{i, t}, \bar{a}_{i, t+1}\right)_{t=0}^{\infty}$ is a solution of program $S_{i}(\bar{p}, \bar{q})$.

In the sequel, we denote for simplicity the equilibrium sequence by $\left(p, q,\left(c_{i}, a_{i}\right)_{i=1}^{m}\right)$. It is easy to prove the existence of reduced multipliers $x_{i, t+1} \geq 0$ such that the slackness condition $x_{i, t+1} a_{i, t+1}=0$ and the asset-pricing (no-arbitrage) condition

$$
\frac{q_{t}}{p_{t}}=\frac{\beta_{i} u_{i}^{\prime}\left(c_{i, t+1}\right)}{u_{i}^{\prime}\left(c_{i, t}\right)}\left[\frac{q_{t+1}}{p_{t+1}}+\frac{v_{i, t}^{\prime}\left(a_{i, t+1}\right)}{u_{i}^{\prime}\left(c_{i, t+1}\right)}+F_{i, t+1}^{\prime}\left(a_{i, t+1}\right)+x_{i, t+1}\right]
$$

As above, we introduce the transition discount factors (individual and maximal) from time $t$ to time $t+1$ :

$$
\gamma_{i, t+1}:=\frac{\beta_{i} u_{i}^{\prime}\left(c_{i, t+1}\right)}{u_{i}^{\prime}\left(c_{i, t}\right)} \text { and } \gamma_{t+1}:=\max _{i \in I} \frac{\beta_{i} u_{i}^{\prime}\left(c_{i, t+1}\right)}{u_{i}^{\prime}\left(c_{i, t}\right)}
$$

and the corresponding compound discount factors: $Q_{i, t}:=\gamma_{i, 1} \cdots \gamma_{i, t}$ and $Q_{t}:=\gamma_{1} \cdots \gamma_{t}$, with $Q_{i, 0}:=Q_{0}:=1$.

Transversality conditions still hold

Lemma 5. $\lim _{t \rightarrow \infty}\left(Q_{i, t} a_{i, t+1} q_{t} / p_{t}\right)=0$ for any $i$.

For each $t$, individual dividend $d_{i, t}$ of agent $i$ is defined by:

$$
d_{i, t}:=\frac{v_{i, t}^{\prime}\left(a_{i, t}\right)}{u_{i}^{\prime}\left(c_{i, t}\right)}+F_{i, t}^{\prime}\left(a_{i, t}\right)+x_{i, t}
$$

We then define the sequence of dividends $\left(d_{t}\right)$ through the asset-pricing equation

$$
\frac{q_{t}}{p_{t}}=\gamma_{t+1}\left(\frac{q_{t+1}}{p_{t+1}}+d_{t+1}\right)
$$


It is easy to see that $d_{t} \in\left[\underline{d}_{t}, \bar{d}_{t}\right]$, where

$$
\underline{d}_{t}:=\min _{i \in I}\left\{\frac{v_{i, t}^{\prime}\left(a_{i, t}\right)}{u_{i}^{\prime}\left(c_{i, t}\right)}+F_{i, t}^{\prime}\left(a_{i, t}\right)\right\} \text { and } \bar{d}_{t}:=\max _{i \in I}\left\{\frac{v_{i, t}^{\prime}\left(a_{i, t}\right)}{u_{i}^{\prime}\left(c_{i, t}\right)}+F_{i, t}^{\prime}\left(a_{i, t}\right)\right\}
$$

By using the approaches in Sections 3 and 4, we can obtain similar results (about bubbles, individual bubbles, and strong bubbles) as the ones with land and house. The difference here is that the endogenous dividends in this general model take into account both roles of the asset: input and utility.

\section{Conclusion and further discussions}

We have introduced different concepts of land and housing bubbles, including individual and strong bubbles. While strong bubbles never occur in our model, bubbles may exist but they are ruled out if agents' expected values coincide with the fundamental value of land. Interestingly, there is always an agent whose expected value of land equals the land equilibrium price. Some explicit examples of bubbles are provided to illustrate these theoretical outcomes. Land bubbles may arise when agents experience endowment fluctuations and the ratio between fruits of land and endowments tends to zero. Similarly, housing bubbles may arise if the endowments fluctuate and the housing preference rate converges to zero.

\section{Further discussions (bubbles and efficiency)}

Although the results on land and house bubbles are quite similar, we would like to point out that different assets may generate very different bubbles. Readers are referred to Bosi et al (2015a) where they show that bubbles of capita good are ruled out if borrowing constraints of agents are not binding while bubbles of aggregate good may appear even when the financial market is perfect.

Another interesting issue is the connection between the existence of bubbles and the efficiency.

First, let us discuss about pure bubbles, i.e., bubbles in the asset which pays no dividend. There is a large literature on this kind of bubble and most of papers focus on OLG frameworks. In a standard OLG model of bubbles, Tirole (1985) shows that a pure bubble may occur only if the economy is inefficient. ${ }^{6}$ However, Farhi and Tirole (2012) points out that with imperfect capital markets, bubbles are possible even when the economy is efficient.

Second, we discuss the connection between physical capital bubble (Becker et al., 2015) and the efficiency of Ramsey equilibrium. ${ }^{7}$ In an infinite-horizon model with stationary technologies, Becker et al. (2015) prove that physical capital bubbles are ruled out. In a similar framework, Becker et al. (2014) provide an example where a three-cycle equilibrium is inefficient. One can prove that there is no physical capital bubble in Becker et al. (2014). This shows that an inefficient bubbleless equilibrium may exist.

With non-stationary technologies, Bosi et al (2015a) give an example where equilibrium is efficient and bubbles occur, and another example where equilibrium is efficient and bubbles are ruled out. These examples suggest that there is no causal relationship between the existence of physical capital bubble and the efficiency of Ramsey equilibrium.

\footnotetext{
${ }^{6}$ According to Tirole (1985), an allocation is efficient if it is not possible to improve the welfare of all generations (and, this, strictly for at least one of them).

${ }^{7} \mathrm{~A}$ Ramsey equilibrium is efficient if its capital path is efficient in the sense of Malinvaud (1953).
} 
Let us now come back to our framework. The question about the (constrained) efficiency in infinite-horizon general equilibrium models is matter of a long debate. Until now, we didn't provide a general sufficient condition for the inefficiency of equilibria.

If we define the efficiency of equilibrium in terms of equilibrium capital paths, we may use Cass (1972) where he gives a necessary and sufficient condition for the efficiency of capital paths. However, Cass (1972) considers only the capital paths (with a single technology) that are bounded away from zero.

In this respect, we raise two issues and leave them for future research: (1) checking whether any equilibrium in our framework is efficient, (2) bridging the existence of land bubble and the efficiency of equilibrium. In order to solve these fundamental problems, we may use the methods introduced by Cass (1972) and Balasko and Shell (1980). ${ }^{8}$

\section{Appendix: Proofs for Sections 3 and 4}

Proof of Lemma 2. $\lim _{t \rightarrow \infty}\left(Q_{i, t} l_{i, t+1} q_{t} / p_{t}\right)=0$ and $\lim _{t \rightarrow \infty}\left[\beta_{i}^{t} u_{i}^{\prime}\left(c_{i, t}\right) l_{i, t+1} q_{t} / p_{t}\right]=0$ are equivalent. We say that $l_{i}$ is feasible if, for every $t, l_{i, t} \geq 0$ and $q_{t} l_{i, t+1} \leq p_{t} e_{i, t}+q_{t} l_{i, t}+p_{t} F_{i}\left(l_{i, t}\right)$. Note that if $l_{i}$ is feasible then $\left(l_{i, 0}, l_{i, 1}, \ldots, l_{i, t-1}, \lambda l_{i, t}, \lambda l_{i, t+1}, \ldots\right)$ is also feasible for each $t \geq 1$ and $\lambda \in(0,1)$. By using the same argument in the proof of Theorem 2.1 by Kamihigashi (2002), we obtain $\lim _{t \rightarrow \infty}\left[\beta_{i}^{t} u_{i}^{\prime}\left(c_{i, t}\right) l_{i, t+1} q_{t} / p_{t}\right]=0$.

Proof of Proposition 2. According to (6), a bubble exists if and only if $\lim _{T \rightarrow \infty} Q_{T} q_{T} / p_{T}>0$. According to (5), we have

$$
Q_{t} \frac{q_{t}}{p_{t}}=Q_{t+1} \frac{q_{t+1}}{p_{t+1}}\left(1+\frac{p_{t+1}}{q_{t+1}} d_{t+1}\right)
$$

for any $t$. By consequence,

$$
\frac{q_{0}}{p_{0}}=Q_{1} \frac{q_{1}}{p_{1}}\left(1+\frac{p_{1}}{q_{1}} d_{1}\right)=\cdots=Q_{T} \frac{q_{T}}{p_{T}}\left(1+\frac{p_{T}}{q_{T}} d_{T}\right) \ldots\left(1+\frac{p_{1}}{q_{1}} d_{1}\right)
$$

So, $\lim _{T \rightarrow \infty} Q_{T} q_{T} / p_{T}>0$ if and only if

$$
\lim _{T \rightarrow \infty}\left[\left(1+\frac{p_{T}}{q_{T}} d_{T}\right) \ldots\left(1+\frac{p_{1}}{q_{1}} d_{1}\right)\right]<\infty
$$

or, equivalently, $\sum_{t=1}^{\infty}\left(p_{t} d_{t} / q_{t}\right)=0$.

Proof of Proposition 3. Assume that $Q_{t} / Q_{i, t}$ is uniformly bounded from above. According to Lemma 2, we have

$$
\lim _{t \rightarrow \infty}\left(Q_{t} \frac{q_{t}}{p_{t}} l_{i, t+1}\right)=\lim _{t \rightarrow \infty}\left(\frac{Q_{t}}{Q_{i, t}} Q_{i, t} \frac{q_{t}}{p_{t}} l_{i, t+1}\right)=0
$$

for any $i$. Observing that $\sum_{i \in I} l_{i, t+1}=L$ for any $t$, we obtain $\lim _{t \rightarrow \infty}\left(Q_{t} q_{t} / p_{t}\right)=0$.

Proof of Proposition 6. $Q_{t} \geq Q_{i, t}$ implies $\lim _{t \rightarrow \infty}\left(Q_{t} q_{t} / p_{t}\right) \geq \lim _{t \rightarrow \infty}\left(Q_{i, t} q_{t} / p_{t}\right)$. However, we have $F V_{i}+\lim _{t \rightarrow \infty}\left(Q_{i, t} q_{t} / p_{t}\right)=q_{0} / p_{0}=F V_{0}+\lim _{t \rightarrow \infty}\left(Q_{t} q_{t} / p_{t}\right)$. By consequence, we get $F V_{0} \leq$ $F V_{i}$ for any $i$. Therefore, if $i$ - land bubbles exist for some agent $i$ then land bubbles exist.

We now assume that $F V_{0}=F V_{i}$ for any $i$, which implies $\lim _{t \rightarrow \infty}\left(Q_{t} q_{t} / p_{t}\right)=\lim _{t \rightarrow \infty}\left(Q_{i, t} q_{t} / p_{t}\right)$. If land bubbles exist, then

$$
\lim _{t \rightarrow \infty}\left(Q_{t} \frac{q_{t}}{p_{t}}\right)=\lim _{t \rightarrow \infty}\left(Q_{i, t} \frac{q_{t}}{p_{t}}\right) \in\left(0, \frac{q_{0}}{p_{0}}\right)
$$

Thus, we find $\lim _{t \rightarrow \infty}\left(Q_{i, t} / Q_{t}\right)=1$. We obtain $\lim _{t \rightarrow \infty}\left(Q_{t} q_{t} / p_{t}\right)=0$ according to Proposition 3 .

${ }^{8}$ We observe that (1) Balasko and Shell (1980) consider OLG models and (2) the technique introduced by Cass (1972) doesn't apply directly to a framework with many producers as ours. 
Lemma 6. If a sequence $\left(p_{t}, q_{t},\left(c_{i, t}, l_{i, t+1}, \mu_{i, t}\right)_{i \in I}\right)_{t}$ satisfies:

(i) positivity of prices $\left(p_{t}=1\right.$ and $q_{t}>0$ for any $\left.t\right)$ and non-negativity of allocations and multipliers $\left(c_{i, t}>0, l_{i, t+1} \geqslant 0\right.$ and $\mu_{i, t} \geqslant 0$ for any $i$ and $\left.t\right)$;

(ii) asset-pricing conditions

$$
q_{t}=\frac{\beta_{i} u_{i}^{\prime}\left(c_{i, t+1}\right)}{u_{i}^{\prime}\left(c_{i, t}\right)}\left[q_{t+1}+F_{i, t}^{\prime}\left(l_{i, t+1}\right)\right]+\mu_{i, t+1}
$$

and slackness conditions $\mu_{i, t+1} l_{i, t+1}=0$ for any $i$ and $t$;

(iii) transversality conditions: $\lim _{t \rightarrow \infty}\left[\beta_{i}^{t} u_{i}^{\prime}\left(c_{i, t}\right) q_{t} l_{i, t+1}\right]=0$ for any $i$;

(iv) budget constraints: $c_{i, t}+q_{t} l_{i, t+1}=e_{i, t}+q_{t} l_{i, t}+F_{i, t}\left(l_{i, t}\right)$ for any $i$ and $t$;

(vi) market clearing: $L=\sum_{i \in I} l_{i, t}$ for any $t$;

then, the sequence of prices and allocations $\left(p_{t}, q_{t},\left(c_{i, t}, l_{i, t+1}\right)_{i \in I}\right)_{t}$ is an equilibrium for the economy with land.

Proof of Lemma 6. It is easy to see that market clearing conditions are satisfied. We now prove the optimality of the agents' plan. Let $\left(c_{i}^{\prime}, l_{i}^{\prime}\right) \geq 0$ be a plan satisfying all the budget constraints and $l_{i, 0}^{\prime}=l_{i, 0}$. We have

$$
\begin{aligned}
\Delta_{T}:= & \sum_{t=0}^{T} \beta_{i}^{t}\left[u_{i}\left(c_{i, t}\right)-u_{i}\left(c_{i, t}^{\prime}\right)\right] \geq \sum_{t=0}^{T} \beta_{i}^{t} u_{i}^{\prime}\left(c_{i, t}\right)\left(c_{i, t}-c_{i, t}^{\prime}\right) \\
= & \sum_{t=0}^{T} \beta_{i}^{t} u_{i}^{\prime}\left(c_{i, t}\right)\left[q_{t}\left(l_{i, t}-l_{i, t}^{\prime}\right)+F_{i, t}\left(l_{i, t}\right)-F_{i, t}\left(l_{i, t}^{\prime}\right)-q_{t}\left(l_{i, t+1}-l_{i, t+1}^{\prime}\right)\right] \\
\geq & \sum_{t=0}^{T} \beta_{i}^{t} u_{i}^{\prime}\left(c_{i, t}\right)\left[q_{t}+F_{i, t}^{\prime}\left(l_{i, t}\right)\right]\left(l_{i, t}-l_{i, t}^{\prime}\right)-\sum_{t=0}^{T} \beta_{i}^{t} u_{i}^{\prime}\left(c_{i, t}\right) q_{t}\left(l_{i, t+1}-l_{i, t+1}^{\prime}\right) \\
= & \sum_{t=1}^{T}\left(\beta_{i}^{t} u_{i}^{\prime}\left(c_{i, t}\right)\left[q_{t}+F_{i, t}^{\prime}\left(l_{i, t}\right)\right]-\beta_{i}^{t-1} u_{i}^{\prime}\left(c_{i, t-1}\right) q_{t-1}\right)\left(l_{i, t}-l_{i, t}^{\prime}\right) \\
& -\beta_{i}^{T} u_{i}^{\prime}\left(c_{i, T}\right) q_{T}\left(l_{i, T+1}-l_{i, T+1}^{\prime}\right) .
\end{aligned}
$$

We obtain $\beta_{i}^{t} u_{i}^{\prime}\left(c_{i, t}\right)\left[q_{t}+F_{i, t}^{\prime}\left(l_{i, t}\right)\right]-\beta_{i}^{t-1} u_{i}^{\prime}\left(c_{i, t-1}\right) q_{t-1}=-\mu_{i, t} \beta_{i}^{t-1} u_{i}^{\prime}\left(c_{i, t-1}\right)$ according to (16). By using this and the fact that $\mu_{i, t} l_{i, t}=0$ for any $t$, we have

$$
\begin{aligned}
\Delta_{T} & \geq-\sum_{t=1}^{T} \mu_{i, t} \beta_{i}^{t-1} u_{i}^{\prime}\left(c_{i, t-1}\right)\left(l_{i, t}-l_{i, t}^{\prime}\right)+\beta_{i}^{T} u_{i}^{\prime}\left(c_{i, T}\right) q_{T}\left(l_{i, T+1}^{\prime}-l_{i, T+1}\right) \\
& =\sum_{t=1}^{T} \beta_{i}^{t-1} u_{i}^{\prime}\left(c_{i, t-1}\right) \mu_{i, t} l_{i, t}^{\prime}+\beta_{i}^{T} u_{i}^{\prime}\left(c_{i, T}\right) q_{T}\left(l_{i, T+1}^{\prime}-l_{i, T+1}\right) \\
& \geq-\beta_{i}^{T} u_{i}^{\prime}\left(c_{i, T}\right) q_{T} l_{i, T+1} .
\end{aligned}
$$

$\sum_{t=0}^{\infty} \beta_{i}^{t} u_{i}\left(c_{i, t}\right)<\infty$ and $\lim _{t \rightarrow \infty}\left[\beta_{i}^{T} u_{i}^{\prime}\left(c_{i, T}\right) q_{T} l_{i, T+1}\right]=0$ entail that the sum $\sum_{t=0}^{\infty} \beta_{i}^{t} u_{i}\left(c_{i, t}^{\prime}\right)$ is finite. Therefore, we get $\sum_{t=0}^{\infty} \beta_{i}^{t} u_{i}\left(c_{i, t}\right) \geq \sum_{t=0}^{\infty} \beta_{i}^{t} u_{i}\left(c_{i, t}^{\prime}\right)$.

Proof for the example in Section 3.2. It is easy to see that the market clearing conditions are satisfied. 
We check the first-order conditions:

$$
\begin{aligned}
q_{2 t} & =\frac{\beta_{B} u_{B}^{\prime}\left(c_{B, 2 t+1}\right)}{u_{B}^{\prime}\left(c_{B, 2 t}\right)}\left(q_{2 t+1}+B_{2 t+1}\right) \geq \frac{\beta_{A} u_{A}^{\prime}\left(c_{A, 2 t+1}\right)}{u_{A}^{\prime}\left(c_{A, 2 t}\right)}\left(q_{2 t+1}+A_{2 t+1}\right) \\
q_{2 t-1} & =\frac{\beta_{A} u_{A}^{\prime}\left(c_{A, 2 t}\right)}{u_{A}^{\prime}\left(c_{A, 2 t-1}\right)}\left(q_{2 t}+A_{2 t}\right) \geq \frac{\beta_{B} u_{B}^{\prime}\left(c_{B, 2 t}\right)}{u_{B}^{\prime}\left(c_{B, 2 t-1}\right)}\left(q_{2 t}+B_{2 t}\right)
\end{aligned}
$$

The equality in (17) holds because

$$
\begin{aligned}
\frac{\beta_{B} u_{B}^{\prime}\left(c_{B, 2 t+1}\right)}{u_{B}^{\prime}\left(c_{B, 2 t}\right)}\left(q_{2 t+1}+B_{2 t+1}\right) & =\frac{\beta_{B}\left(e_{B, 2 t}-q_{2 t}\right)}{q_{2 t+1}+B_{2 t+1}}\left(q_{2 t+1}+B_{2 t+1}\right) \\
& =\beta_{B}\left(e_{B, 2 t}-q_{2 t}\right)=q_{2 t}
\end{aligned}
$$

Now, we prove the inequality in (17). We have

$$
\begin{aligned}
& \frac{\beta_{A} u_{A}^{\prime}\left(c_{A, 2 t+1}\right)}{u_{A}^{\prime}\left(c_{A, 2 t}\right)}\left(q_{2 t+1}+A_{2 t+1}\right)=\frac{\beta_{A}\left(q_{2 t}+A_{2 t}\right)}{e_{A, 2 t+1}-q_{2 t+1}}\left(q_{2 t+1}+A_{2 t+1}\right) \\
& =\frac{\beta_{A}\left(\frac{\beta_{B}}{1+\beta_{B}} e_{B, 2 t}+A_{2 t}\right)}{\frac{1}{1+\beta_{A}} e_{A, 2 t+1}}\left(\frac{\beta_{A}}{1+\beta_{A}} e_{A, 2 t+1}+A_{2 t+1}\right)
\end{aligned}
$$

By consequence, the inequality in (17) is equivalent to

$$
\beta_{A}\left(\frac{\beta_{B} e_{B, 2 t}}{1+\beta_{B}}+A_{2 t}\right)\left(\frac{\beta_{A} e_{A, 2 t+1}}{1+\beta_{A}}+A_{2 t+1}\right) \leq \beta_{B} \frac{e_{B, 2 t}}{1+\beta_{B}} \frac{e_{A, 2 t+1}}{1+\beta_{A}}
$$

that is (9).

We have

$$
\begin{aligned}
\frac{\beta_{B} u_{B}^{\prime}\left(c_{B, 2 t}\right)}{u_{B}^{\prime}\left(c_{B, 2 t-1}\right)}\left(q_{2 t}+B_{2 t}\right) & =\frac{\beta_{B}\left(q_{2 t-1}+B_{2 t-1}\right)}{e_{B, 2 t}-q_{2 t}}\left(q_{2 t}+B_{2 t}\right) \\
& =\frac{\beta_{B}\left(\frac{\beta_{A}}{1+\beta_{A}} e_{A, 2 t-1}+B_{2 t-1}\right)}{\frac{1}{1+\beta_{B}} e_{B, 2 t}}\left(\frac{\beta_{B}}{1+\beta_{B}} e_{B, 2 t}+B_{2 t}\right)
\end{aligned}
$$

By consequence, the inequality in (18) is equivalent to

$$
\beta_{B}\left(\frac{\beta_{A} e_{A, 2 t-1}}{1+\beta_{A}}+B_{2 t-1}\right)\left(\frac{\beta_{B} e_{B, 2 t}}{1+\beta}+B_{2 t}\right) \leq \beta_{A} \frac{e_{B, 2 t}}{1+\beta_{B}} \frac{e_{A, 2 t-1}}{1+\beta_{A}}
$$

that is (10).

We now check the transversality conditions:

$$
\begin{aligned}
\beta_{A}^{2 t} u_{A}^{\prime}\left(c_{A, 2 t}\right) q_{2 t} l_{A, 2 t+1} & =0 \\
\beta_{A}^{2 t-1} u_{A}^{\prime}\left(c_{A, 2 t-1}\right) q_{2 t-1} l_{A, 2 t} & =\frac{\beta_{A}^{2 t-1}}{c_{A, 2 t-1}} q_{2 t-1}=\frac{1}{1+\beta_{A}} \beta_{A}^{2 t} \rightarrow 0
\end{aligned}
$$

Similarly,

$$
\begin{aligned}
\beta_{B}^{2 t} u_{B}^{\prime}\left(c_{B, 2 t}\right) q_{2 t} l_{B, 2 t+1} & =\frac{1}{1+\beta_{B}} \beta_{B}^{2 t+1} \rightarrow 0 \\
\beta_{B}^{2 t-1} u_{B}^{\prime}\left(c_{B, 2 t-1}\right) q_{2 t-1} l_{B, 2 t} & =0
\end{aligned}
$$

Finally, it is easy to see that conditions (11) and (12) imply

$$
\begin{aligned}
\gamma_{2 t} & =\frac{\beta_{A} u_{A}^{\prime}\left(c_{A, 2 t}\right)}{u_{A}^{\prime}\left(c_{A, 2 t-1}\right)} \geq \frac{\beta_{B} u_{B}^{\prime}\left(c_{B, 2 t}\right)}{u_{B}^{\prime}\left(c_{B, 2 t-1}\right)} \\
\gamma_{2 t+1} & =\frac{\beta_{B} u_{B}^{\prime}\left(c_{B, 2 t+1}\right)}{u_{B}^{\prime}\left(c_{B, 2 t}\right)} \geq \frac{\beta_{A} u_{A}^{\prime}\left(c_{A, 2 t+1}\right)}{u_{A}^{\prime}\left(c_{A, 2 t}\right)}
\end{aligned}
$$


The result of Lemma 6 also holds for housing.

Lemma 7 (sufficient equilibrium condition in housing economies). If a sequence $\left(p_{t}, q_{t},\left(c_{i, t}, h_{i, t+1}, \nu_{i, t}\right)_{i \in I}\right)_{t}$ satisfies:

(i) positivity of prices ( $p_{t}=1$ and $q_{t}>0$ for any $t$ ) and non-negativity of allocations and multipliers $\left(c_{i, t}>0, h_{i, t+1} \geqslant 0\right.$ and $\nu_{i, t} \geqslant 0$ for any $i$ and $\left.t\right)$;

(ii) asset-pricing conditions

$$
q_{t}=\frac{\beta_{i} u_{i}^{\prime}\left(c_{i, t+1}\right)}{u_{i}^{\prime}\left(c_{i, t}\right)}\left[q_{t+1}+\frac{v_{i, t+1}^{\prime}\left(h_{i, t+1}\right)}{u_{i}^{\prime}\left(c_{i, t+1}\right)}\right]+\nu_{i, t+1}
$$

and slackness conditions $\nu_{i, t+1} h_{i, t+1}=0$ for any $i$ and $t$;

(iii) transversality conditions: $\lim _{t \rightarrow \infty}\left[\beta_{i}^{t} u_{i}^{\prime}\left(c_{i, t}\right) q_{t} h_{i, t+1}\right]=0$ for any $i$

(iv) budget constraints: $c_{i, t}+q_{t} h_{i, t+1}=e_{i, t}+q_{t} h_{i, t}$ for any $i$ and $t$;

(vi) market clearing: $\sum_{i \in I} H_{i, t}=H$ for any $t$;

then, the sequence of prices and allocations $\left(p_{t}, q_{t},\left(c_{i, t}, h_{i, t+1}\right)_{i \in I}\right)_{t}$ is an equilibrium for the housing economy.

\section{Existence of equilibrium}

We adapt the proofs of Becker et al. (2015) and Le Van and Pham (2015). We consider nonstationary production functions $F_{i, t}$ depending on $t$.

Existence of equilibrium in a truncated economy

We define a $T$ - truncated economy $\mathcal{E}^{T}$ as $\mathcal{E}$ but without activities from period $T+1$ on, that is we set $c_{i, t}=l_{i, t}=0$ for $i=1, \ldots, m$ and $t \geq T+1$.

Then, we define a bounded economy $\mathcal{E}_{b}^{T}$ as $\mathcal{E}^{T}$ but sequences of consumption $\left(c_{i, t}\right)_{t=0}^{T}$ and land holdings $\left(l_{i, t}\right)_{t=1}^{T}$ lie in the following bounded sets $\mathcal{C}_{i}:=\left[0, B_{c}\right]^{T+1}$ and $\mathcal{L}_{i}:=\left[0, B_{l}\right]^{T}$ respectively, with $B_{c}>\max _{t \leq T} \sum_{i=1}^{m}\left[e_{i, t}+F_{i, t}\left(B_{l}\right)\right]$ and $B_{l}>L$. Therefore, the economy $\mathcal{E}_{b}^{T}$ depends on bounds $B_{c}$ and $B_{l}$. We write $\mathcal{E}_{b}^{T}\left(B_{c}, B_{l}\right)$.

Let us denote $\mathcal{X}_{b}:=\mathcal{C}_{i} \times \mathcal{L}_{i}$ and $\mathcal{X}:=\left(\mathcal{X}_{b}\right)^{T+1}$, and define

$$
\begin{aligned}
& \mathcal{P}:=\left\{z_{0}=(p, q): q_{T}=0 ; p_{t}, q_{t} \geq 0 ; p_{t}+q_{t}=1 ; t=0, \ldots, T\right\} \\
& \Phi:=\mathcal{P} \times \mathcal{X}
\end{aligned}
$$

An element $z \in \Phi$ is a list $z=\left(z_{i}\right)_{i=0}^{m}$ with $z_{0}:=(p, q)$ and $z_{i}:=\left(c_{i}, l_{i}\right)$ for each $i=1, \ldots, m$.

Remark 7. If $z \in \Phi$ is an equilibrium for the economy $\mathcal{E}$ then $c_{i, t} \in\left[0, B_{c}\right), l_{i, t} \in[0, L]$.

Proposition 9. Under our assumptions, there exists an equilibrium $\left(p, q,\left(c_{i}, l_{i}\right)_{i=1}^{m}\right)$ with $p_{t}+q_{t}=1$ for the economy $\mathcal{E}_{b}^{T}\left(B_{c}, B_{l}\right)$.

Proof. We introduce the budget sets:

$$
\begin{gathered}
C_{i}^{T}(p, q):=\left\{\left(c_{i, t}, l_{i, t+1}\right)_{t=0}^{T} \in \mathcal{X}: l_{i, T+1}, b_{i, T+1}=0,\right. \\
\left.p_{t} c_{i, t}+q_{t} l_{i, t+1} \leq p_{t} e_{i, t}+p_{t} F_{i, t}\left(l_{i, t}\right)+q_{t} l_{i, t} \forall t\right\} \\
B_{i}^{T}(p, q):=\left\{\left(c_{i, t}, l_{i, t+1}\right)_{t=0}^{T} \in \mathcal{X}: l_{i, T+1}, b_{i, T+1}=0,\right. \\
\left.p_{t} c_{i, t}+q_{t} l_{i, t+1}<p_{t} e_{i, t}+p_{t} F_{i, t}\left(l_{i, t}\right)+q_{t} l_{i, t} \forall t\right\}
\end{gathered}
$$


Since $e_{i, 0}, l_{i, 0}>0$ and $\left(p_{0}, q_{0}\right) \neq(0,0)$, we always have $p_{0} e_{i, 0}+p_{0} F_{i, 0}\left(l_{i, 0}\right)+q_{0} l_{i, 0}>0$. By consequence, $B_{i}^{T}(p, q) \neq \emptyset$ and $\bar{B}_{i}^{T}(p, q)=C_{i}^{T}(p, q)$.

Since $B_{i}^{T}(p, q)$ is nonempty and has an open graph, $B_{i}^{T}(p, q)$ is lower semi-continuous correspondence on $\mathcal{P}$. And we also have $C_{i}^{T}(p, q)$ is continuous on $\mathcal{P}$ with compact convex values.

We introduce the correspondences. We define $\varphi_{0}$ (for additional agent 0 ) $: \mathcal{X} \rightarrow 2^{\mathcal{P}}$ :

$$
\varphi_{0}\left(\left(z_{i}\right)_{i=1}^{m}\right):=\arg \max _{(p, q) \in \mathcal{P}}\left(\sum_{t=0}^{T} p_{t} \sum_{i=1}^{m}\left[c_{i, t}-e_{i, t}-F_{i, t}\left(l_{i, t}\right)\right]+\sum_{t=0}^{T-1} q_{t} \sum_{i=1}^{m}\left(l_{i, t+1}-l_{i, t}\right)\right)
$$

For $i=1, \ldots, m$, we define $\varphi_{i}: \mathcal{P} \rightarrow 2^{\mathcal{X}}$ :

$$
\varphi_{i}((p, q)):=\arg \max _{\left(c_{i}, l_{i}\right) \in C_{i}(p, q)} \sum_{t=0}^{T} \beta_{i}^{t} u_{i}\left(c_{i, t}\right)
$$

The correspondence $\varphi_{i}$ is upper semi-continuous, non-empty, convex and compact-valued for each $i=0, \ldots, m+1$. According to the Kakutani Theorem, there exists $\left(\bar{p}, \bar{q},\left(\bar{c}_{i}, \bar{l}_{i}\right)_{i=1}^{m}\right)$ such that $(\bar{p}, \bar{q}) \in \varphi_{0}\left(\left(\bar{c}_{i}, \bar{l}_{i}\right)_{i=1}^{m}\right)$ and $\left(\bar{c}_{i}, \bar{l}_{i}\right) \in \varphi_{i}((\bar{p}, \bar{q}))$.

It is easy to prove that $\left(\bar{p}, \bar{q},\left(\bar{c}_{i}, \bar{l}_{i}\right)_{i=1}^{m}\right)$ is an equilibrium for the economy $\mathcal{E}_{b}^{T}$.

We apply the argument of Lemma 3 in Le Van and Pham (2015) to prove the existence of equilibrium in unbounded truncated economies.

Proposition 10. An equilibrium $\left(p, q,\left(c_{i}, l_{i}\right)_{i=1}^{m}\right)$, with $p_{t}+q_{t}=1$, of $\mathcal{E}_{b}^{T}$ is an equilibrium for $\mathcal{E}^{T}$.

\section{Existence of equilibrium in an infinite-horizon economy}

Proposition 11. Under Assumptions 1 to 4, there exists an equilibrium in the economy $\mathcal{E}$.

Proof. We have shown that there exists an equilibrium, say $\left(p^{T}, q^{T},\left(c_{i}^{T}, l_{i}^{T}\right)_{i}\right)$, for each truncated economy $\mathcal{E}^{T}$. Recall that $p_{t}^{T}+q_{t}^{T}=1$. It is clear that, for each $t$, we have $c_{i, t}^{T} \in\left(0, W_{t}\right) ; l_{i, t}^{T} \in[0, L]$; $p_{t}^{T}, q_{t}^{T} \in[0,1]$. Therefore, without loss of generality, we can assume that $\left(p^{T}, q^{T},\left(c_{i}^{T}, l_{i}^{T}\right)_{i}\right) \stackrel{T \rightarrow \infty}{\longrightarrow}$ $\left(p, q,\left(c_{i}, l_{i}\right)_{i}\right)$ (for the product topology).

Applying the same argument in the proof of Theorem 1 by Le Van and Pham (2015) or the proof of Theorem 1 by Le Van, Pham, and Vailakis (2014), we obtain that $\left(p, q,\left(c_{i}, l_{i}\right)_{i}\right)$ is an equilibrium for the economy $\mathcal{E}$.

\section{References}

Aoki K., T. Nakajima and K. Nikolov, Safe asset shortages and asset price bubbles, Journal of Mathematical Economics 53, 165-174 (2014).

Hirano T. and N. Yanagawa, Asset bubbles, endogenous growth and financial frictions, Working Paper, University of Tokyo (2013).

Araujo A., R. Novinski and M.R. Pascoa, General equilibrium, wariness and efficient bubbles, Journal of Economic Theory 146, 785-811 (2011).

Araujo A., M.R. Pascoa and J.P. Torres-Martinez, Long-lived collateralized assets and bubbles, Journal of Mathematical Economics 47, 260-271 (2011).

Balasko Y. and K. Shell, The Overlapping Generations Model I: The Case of Pure Exchange without Money, Journal of Economic Theory 23, 281-306 (1980).

Becker R.A., R.S. Dubey and T. Mitra, On Ramsey equilibrium: capital ownership pattern and inefficiency, Economic Theory 55, 565-600 (2014). 
Becker R., S. Bosi, C. Le Van and T. Seegmuller, On existence and bubbles of Ramsey equilibrium with borrowing constraints, Economic Theory 58, 329-353 (2015).

Bosi S., C. Le Van and N-S. Pham, Asset bubbles and efficiency in a generalized two-sector model, LEM working paper (2015).

Bosi S., C. Le Van and N-S. Pham, Intertemporal equilibrium with heterogeneous agents, endogenous dividends and borrowing constraints, EPEE working paper (2015).

Brunnermeier M.K. and M. Oehmke, Bubbles, financial crises, and systemic risk, Handbook of the Economics of Finance, vol. 2 (2012).

Cass D., On capital overaccumulation in the aggregative, neoclassical model of economic growth: A complete characterization, Journal of Economic Theory 4, 200-223 (1972).

Farhi E. and J. Tirole, Bubbly liquidity, Review of Economic Studies 79, 678-706 (2012).

Hirano T. and N. Yanagawa, Asset bubbles, endogenous growth and financial frictions, Working Paper, University of Tokyo (2013).

Huang K.X.D. and J. Werner, Asset price bubbles in Arrow-Debreu and sequential equilibrium, Economic Theory 15, 253-278 (2000).

Kamihigashi T., A simple proof of the necessity of the transversality condition, Economic Theory 20, 427-433 (2002).

Kocherlakota N.R., Bubbles and constraints on debt accumulation, Journal of Economic Theory, 57, 245-256 (1992).

Le Van C. and N.S. Pham, Financial asset bubble with heterogeneous agents and endogenous borrowing constraints, Working paper (2014).

Le Van C., and N.S. Pham, Intertemporal equilibrium with financial asset and physical capital, Economic Theory (2015).

Malinvaud E., Capital accumulation and efficient allocation of resources, Econometrica 21, 233-268 (1953).

Miao J., Introduction to economic theory of bubbles, Journal of Mathematical Economics 53, 130-136 (2014).

Miao J. and P. Wang, Bubbles and total factor productivity, American Economic Review: Papers and Proceedings 102, 82-87 (2012)

Miao J. and P. Wang, Bubbles and credit constraints, working paper, Boston University (2015).

Montrucchio L., Cass transversality condition and sequential asset bubbles, Economic Theory, 24, 645-663 (2004).

Santos M.S. and M. Woodford, Rational asset pricing bubbles, Econometrica, 65, 19-57 (1997).

Tirole J., On the possibility of speculation under rational expectations, Econometrica 50, 1163-1181 (1982).

Tirole J., Asset bubbles and overlapping generations, Econometrica 53, 1499-1528 (1985).

Weil P., On the possibility of price decreasing bubbles, Econometrica, 58, 1467-1474 (1990).

Werner J., Speculative trade under ambiguity, mimeo (2014). 